LELIS. Henrique Rodrigues; COELHO, Fernando Da Cruz; LEMOS JUNIOR, Eloy Pereira. O impacto das normas de proteção de dados pessoais nos social customer relationship management. Revista Eletrônica Direito e Política, Programa de PósGraduação Stricto Sensu em Ciência Jurídica da UNIVALI, Itajaí, v.16, n.3, $3^{\circ}$ quadrimestre de 2021. Disponível em: www.univali.br/direitoepolitica - ISSN 1980-7791.

\title{
O IMPACTO DAS NORMAS DE PROTEÇÃO DE DADOS PESSOAIS NOS SOCIAL CUSTOMER RELATIONSHIP MANAGEMENT
}

\author{
THE IMPACT OF PERSONAL DATA PROTECTION STANDARDS ON SOCIAL \\ CUSTOMER RELATIONSHIP MANAGEMENT
}

Henrique Rodrigues Lelis ${ }^{1}$

Fernando Da Cruz Coelho²

Eloy Pereira lemos Junior ${ }^{3}$

\section{RESUMO}

Esta pesquisa explora os efeitos que as novas leis de proteção de dados pessoais implantadas no Brasil e na União Europeia podem provocar na atividade empresarial. Para isto, foi realizado um estudo de caso entre 08 empresas que operam com Social-CRM, realizando uma análise da conformidade de seus sistemas de gestão de dados digitais com o determinado pelas de proteção de

\footnotetext{
1 Doutorando em Gestão do Conhecimento e Sistema de Informação pela Universidade FUMEC. Mestre em Proteção dos Direitos Fundamentais pelo Programa de Mestrado em Direito da Universidade de Itaúna. Pós-graduado em Gestão Cultural pela UNA/BH. MBA em Gestão de negócios no contexto empreendedor pelo Instituto de Educação Continuada - IEC da Pontifícia Universidade Católica de Minas Gerais - PUC Minas, interrompido. Graduado em Direito pela Pontifícia Universidade Católica de Minas Gerais - PUC Minas. Membro fundador do grupo de pesquisa Direito, Economia Criativa e Inovação Tecnológica.

2 Doutorando em sistemas de informação e gestão do conhecimento pela Fumec. Mestre em administração pela Fumec. Especialista em criminalidade e segurança pública. Bacharel em Direito. Bacharel em Gestão de Segurança Patrimonial Uni-BH. Coordenador de Segurança Universitária da Universidade FUMEC e Coordenador do Curso Superior de Tecnologia em Gestão de Segurança Privada EaD da FACE/FUMEC

3 Possui doutorado em direito empresarial pela UFMG (2007), mestrado (2002) e especializações (direito interdisciplinar). Foi bolsista da CAPES em estágio doutoral na Universidade Clássica de Lisboa (2005) e como professor pesquisador da FUNDEP-UFMG em 2013. Pós-doutorado em direito pela PUC-MG (2018). Avaliador de cursos de direito pelo INEP-MEC (desde 2010). Professor titular do doutorado, mestrado e graduação em direito da Universidade de Itaúna (desde 2011). Foi professor titular na graduação e especializações de diversas IES. Experiência acadêmica na área de direito privado, com ênfase em direito empresarial e em direitos humanos, pesquisas, pesquisas científicas, em artigos e monografias (TCCS). Autor de artigos científicos na área de direito. Coordenador do grupo de Pesquisa em Direito Privado: Direitos Humanos/Fundamentais; Propriedade Privada/Empresas; Justiça/Funções e Inovações Sociais; e Inteligência competitiva e empreendedorismo. Rondonista e voluntário em causas sociais. Recebeu em 2015 o prêmio Jabuti pelo Livro: Pessoas em Situação de Rua (ISBN 9788567020600), onde escreveu um capítulo sobre seus direitos trabalhistas.
} 
LELIS. Henrique Rodrigues; COELHO, Fernando Da Cruz; LEMOS JUNIOR, Eloy Pereira. O impacto das normas de proteção de dados pessoais nos social customer relationship management. Revista Eletrônica Direito e Política, Programa de PósGraduação Stricto Sensu em Ciência Jurídica da UNIVALI, Itajaí, v.16, n.3, $3^{\circ}$ quadrimestre de 2021. Disponível em: www.univali.br/direitoepolitica - ISSN 1980-7791.

dados pessoais. Exploratória quanto ao objetivo, de natureza qualitativa, objeto tratado a partir de um estudo de caso com amostra não probabilística, coleta de dados a partir de pesquisa bibliográfica, observação assistemática e análise de conteúdo como técnica de análise de dados. Demonstra que a efetividade da lei de proteção de dados pessoais irá depender mais de como o processo de tomada de decisão ocorre dentro das organizações do que do processo de fiscalização do estado. Que sistemas de Social-CRM e compliance digital são temas correlatos e indivisíveis e precisam operar de forma colaborativa. É um estudo transdisciplinar entre direito digital e marketing, contribuindo para uma melhor compreensão dos impactos da lei geral de proteção de dados dentro dos sistemas de gestão empresariais modernos, cada vez mais dependentes do tratamento de dados digitais pessoais para tomada de decisão estratégica. Também contribui para o amadurecimento das teorias ligadas ao compliance digital e Social-CRM, na medida que permitem a visualização de problemas legais concretos.

Palavras Chaves: Direito Digital; General Data Protection Regulation; Lei Geral de Proteção de dados pessoais; Compliance Digital; Social Customer Relationship Management

\section{ABSTRACT}

This research explores the effects that the new personal data protection laws implemented in Brazil and the European Union can have on business activity. For this, a case study was carried out among 08 companies that operate with SocialCRM, performing an analysis of the compliance of their digital data management systems with that determined by the personal data protection. Exploratory as to the objective, of qualitative nature, with an object treated from a case study with a non-probabilistic sample, collecting data from bibliographic research and unsystematic observation and content analysis as a data analysis technique. Demonstrates that companies view partner media as strategic, having their own systems for collecting and processing digital data for commercial purposes. That the effectiveness of the personal data protection law will depend more on how the decision-making process takes place within organizations than on the state's oversight process. Which Social-CRM and digital compliance systems are related and indivisible topics. It is a transdisciplinary study between digital law and marketing, contributing to a better understanding of the impacts of the general data protection law within modern business management systems, increasingly dependent on the processing of personal digital data for strategic decision making. It also contributes to the maturation of theories related to digital compliance and Social-CRM, as they allow the visualization of concrete legal problems.

Keywords: Digital Law; General Data Protection Regulation; General Law on Protection of Personal Data; Digital Compliance; Social Customer Relationship Management 
LELIS. Henrique Rodrigues; COELHO, Fernando Da Cruz; LEMOS JUNIOR, Eloy Pereira. O impacto das normas de proteção de dados pessoais nos social customer relationship management. Revista Eletrônica Direito e Política, Programa de PósGraduação Stricto Sensu em Ciência Jurídica da UNIVALI, Itajaí, v.16, n.3, $3^{\circ}$ quadrimestre de 2021. Disponível em: www.univali.br/direitoepolitica - ISSN 1980-7791.

\section{INTRODUÇÃo}

O direito como instrumento de regulação do fato social deve ser pesquisado de forma transdisciplinar para que, em conjunto com as demais áreas da ciência, consiga visualizar as causas e consequências de sua aplicação.

Por sua vez, Social Customer Relationship Management, compliance digital, gestão da informação e do conhecimento são conceitos correlatos, operando na obtenção de vantagem competitiva empresarial através da coleta e tratamento de dados digitais de usuários de mídias sociais. Face ao crescente uso destes instrumentos, recentemente foram aprovadas leis reguladoras da proteção de dados pessoais no Brasil e na União Europeia. Estas regulamentações provocaram impactos sociais que precisam ser estudados. Dentre eles, visualiza-se a necessidade de estudos relacionados a conformidade dos sistemas de Social-CRM com as diretrizes impostas pela nova legislação, pois, tratando-se de sistemas de gestão empresarial baseados em tratamentos de dados pessoais, a nova lei impõe desafios e exigências aos gestores destes sistemas.

O objetivo desta pesquisa é explorar os efeitos das novas leis de proteção de dados pessoais na atividade empresarial que adotam o Social-CRM. Para isto, foi realizado um estudo de caso entre 08 empresas que trabalham a gestão de relacionamento com clientes dentro do contexto das mídias sociais, realizando uma análise da conformidade de seus sistemas de gestão de dados digitais com o determinado pelas leis brasileiras e da União Europeia.

Com esta proposta, pretende-se visualizar o grau de conformidade dos sistemas de proteção de dados empresariais com as novas diretrizes legais, quais as possíveis causas e consequências das inconformidades encontradas. Tem-se como hipótese que a lei de proteção de dados pessoais exigirá atualizações importantes nos sistemas de gestão do Social-CRM, dentre as quais, contínuo treinamento e aperfeiçoamento dos colaboradores sobre as causas da inconformidades, como preveni-las ou mitigá-las e, principalmente, o treinamento sobre a importância da segurança de dados pessoais como estratégica da gestão empresarial. 
LELIS. Henrique Rodrigues; COELHO, Fernando Da Cruz; LEMOS JUNIOR, Eloy Pereira. O impacto das normas de proteção de dados pessoais nos social customer relationship management. Revista Eletrônica Direito e Política, Programa de PósGraduação Stricto Sensu em Ciência Jurídica da UNIVALI, Itajaí, v.16, n.3, $3^{\circ}$ quadrimestre de 2021. Disponível em: www.univali.br/direitoepolitica - ISSN 1980-7791.

Espera-se com este estudo aprofundar o debate sobre a importância do direito digital, sua transdisciplinaridade e interdependência com outras áreas do pensamento, assim como, aprofundar o conhecimento sobre compliance digital e Social-CRM.

\section{METOdOLOGIA DE PESQUISA}

A presente pesquisa coleta e analisa dados não estruturados, permitindo a compreensão do impacto que o advento de normas de proteção de dados pessoais trouxe no desenvolvimento de sistemas de Social-CRM de organizações empresariais sediadas no Brasil. Ela perfaz o que a metodologia científica define como pesquisa exploratória, na medida que, procura conhecer um fenômeno, familiarizando o pesquisador com os elementos característicos do objeto e dos fatos que o circunda, levando a identificação de outros problemas de pesquisa com maior clareza, a formulação novas hipóteses e realização de novas pesquisas mais estruturadas. De Oliveira (2011); Révillion (2003)

Sua natureza é qualitativa, com o estudo de teorias básicas, doutrinas e dados não estruturados, com propósito de definir e compreender o fenômeno em profundidade. Turato (2005)

Trata-se de um Estudo de caso com amostra não probabilística, com suas teorias dirigidas para o estudo de fenômenos específicos ou situações particulares, no caso em tela, avaliação da conformidade legal de políticas de privacidade de 08 empresas. A amostra foi definida a partir de critérios de acessibilidade dos autores. De Oliveira (2011)

Na coleta de dados, o estudo se serviu da pesquisa bibliográfica para o desenvolvimento do marco teórico e da observação assistemática na análise dos dados para o estudo de caso, pois, não foi empregados métodos específicos para o controle de variáveis que podem ter interferido nos resultados. 
LELIS. Henrique Rodrigues; COELHO, Fernando Da Cruz; LEMOS JUNIOR, Eloy Pereira. O impacto das normas de proteção de dados pessoais nos social customer relationship management. Revista Eletrônica Direito e Política, Programa de PósGraduação Stricto Sensu em Ciência Jurídica da UNIVALI, Itajaí, v.16, n.3, $3^{\circ}$ quadrimestre de 2021. Disponível em: www.univali.br/direitoepolitica - ISSN 1980-7791.

Os dados foram estudados com a técnica de análise de conteúdo, buscando dar sentido e inferência entre a base teórica, legislação e os dados coletados nos casos estudados.

Em resumo, esta pesquisa pode ser definida quanto ao objetivo como exploratória, de natureza qualitativa, com objeto tratado a partir de um estudo de caso com amostra não probabilística, coletando dados a partir de pesquisa bibliográfica e observação assistemática e análise de conteúdo como técnica de análise de dados.

O caminho metodológico teve início com o estudo bibliográfico, construindo o marco teórico da pesquisa. Em seguida, foi realizada a escolha das empresas que serviriam de objeto do estudo de caso, seguindo 4 critérios definidos pelos autores: (1) Empresas com atuação no ramo de indústria de alimentos no Brasil e União Europeia; (2) Empresas com matriz situada no Brasil e União Europeia; (3) Empresa com atuação em pelo menos 5 estados brasileiros e União Europeia; (4) Possuem perfil de mídia social oficial no Facebook. (5) No site oficial ou em seu perfil social no Facebook, a empresa coleta dados pessoais dos usuários.

A escolha das empresas participantes foi aleatória. A partir de pesquisas no google, foram filtradas 8 empresas que se encaixam nos critérios acima descritos. Cinco empresas criadas e com matriz no Brasil e três empresas criadas e com matriz na União Europeia.

Tendo em mente que o problema de pesquisa é visualizar possíveis violações e inconformidades dos sistemas de gestão de relacionamento com cliente pautados em plataformas digitais com a legislação de proteção de dados em vigor, e como estas inconformidades podem impactar o desenvolvimento dos sistemas de SocialCRM, foi construído o quadro avaliativo abaixo.

\begin{tabular}{|c|c|c|c|c|}
\hline Pergunta - Enquadramento Legal & $\begin{array}{l}\text { Si } \\
\mathbf{m}\end{array}$ & Não & Artigo da LGPD & $\begin{array}{c}\text { Artigo da } \\
\text { GDPR }\end{array}$ \\
\hline $\begin{array}{l}\text { 1. A empresa realiza coleta e tratamento de } \\
\text { dados pessoais de cidadãos brasileiros e } \\
\text { europeus com finalidade comercial em } \\
\text { plataformas digitais? }\end{array}$ & & $\begin{array}{c}\text { Art. 3a, Inciso I e } \\
\text { II. }\end{array}$ & Art. $2^{a}$ \\
\hline Pergunta - Inconformidade Legal & $\begin{array}{l}\text { Si } \\
\mathbf{m}\end{array}$ & Não & Artigo da LGPD & $\begin{array}{c}\text { Artigo da } \\
\text { GDPR }\end{array}$ \\
\hline
\end{tabular}


LELIS. Henrique Rodrigues; COELHO, Fernando Da Cruz; LEMOS JUNIOR, Eloy Pereira. O impacto das normas de proteção de dados pessoais nos social customer relationship management. Revista Eletrônica Direito e Política, Programa de PósGraduação Stricto Sensu em Ciência Jurídica da UNIVALI, Itajaí, v.16, n.3, $3^{\circ}$ quadrimestre de 2021. Disponível em: www.univali.br/direitoepolitica - ISSN 1980-7791.

\begin{tabular}{|c|c|c|}
\hline $\begin{array}{l}\text { 2. A empresa possui formulário para } \\
\text { consentimento expresso do titular para } \\
\text { coleta de dados pessoais? }\end{array}$ & Art. 7a, Inciso I. & Art. $7^{a}$. \\
\hline $\begin{array}{l}\text { 3. A empresa apresenta informação clara } \\
\text { de que a coleta de dados pessoais é } \\
\text { utilizada para fins de execução de Social- } \\
\text { CRM? }\end{array}$ & $\begin{array}{c}\text { Art. 6a, Inciso I } \\
\text { e VI. }\end{array}$ & $\begin{array}{l}\text { Art. } 7^{a} \text {. } \\
\text { Art. } 12 \text {. }\end{array}$ \\
\hline $\begin{array}{l}\text { 4. A empresa fornece sistema de } \\
\text { comunicação/ contato de fácil acesso entre } \\
\text { Controlador/ Encarregado e o titular de } \\
\text { dados pessoais? }\end{array}$ & $\begin{array}{c}\text { Art. 6a, Inciso IV } \\
\text { e X. }\end{array}$ & $\begin{array}{l}\text { Art. } 12 . \\
\text { Art. } 13 . \\
\text { Art. } 14 .\end{array}$ \\
\hline $\begin{array}{l}\text { 5. A empresa possui mecanismo de } \\
\text { bloqueio/autorização dos responsáveis } \\
\text { legais, quando da coleta de dados pessoais } \\
\text { de menores de } 16 \text { anos de idade? }\end{array}$ & $\begin{array}{c}\text { Art. } 14, \\
\text { parágrafo } 6 \text { a. }\end{array}$ & Art. $8^{a}$. \\
\hline $\begin{array}{l}\text { 6. Os dados pessoais sensíveis coletados } \\
\text { nas plataformas digitais da empresa estão } \\
\text { protegidos por sistemas de segurança da } \\
\text { informação, de maneira que o usuário } \\
\text { externo não pode visualizá-los quando do } \\
\text { manuseio do sistema? }\end{array}$ & $\begin{array}{l}\text { Art. } 6^{\text {a }} \text {, Inciso } \\
\text { VII. }\end{array}$ & Art. 9a. \\
\hline $\begin{array}{l}\text { 7. A empresa obtém autorização expressa } \\
\text { para transferência e compartilhamento de } \\
\text { dados pessoais coletados para outros } \\
\text { controladores? }\end{array}$ & Art. 7a, Inciso I. & $\begin{array}{l}\text { Art. } 13 . \\
\text { Art. } 14 .\end{array}$ \\
\hline $\begin{array}{l}\text { 8. A empresa disponibiliza informações } \\
\text { sobre seu programa de compliance digital } \\
\text { ou sistemas de controle e segurança da } \\
\text { informação? }\end{array}$ & $\begin{array}{l}\text { Art. 6a, Inciso VI } \\
\text { e X. }\end{array}$ & $\begin{array}{l}\text { Art. } 13 . \\
\text { Art. } 14 .\end{array}$ \\
\hline $\begin{array}{l}\text { 9. A empresa disponibiliza informações } \\
\text { claras sobre o direito do titular de dados } \\
\text { pessoais de revogar, retificar ou se opor a } \\
\text { coleta e tratamento de dados pessoais? }\end{array}$ & $\begin{array}{c}\text { Art. } 8^{a}, \\
\text { Parágrafo } 5^{a} \text {. }\end{array}$ & Art. 21. \\
\hline
\end{tabular}

As perguntas foram elaboradas de modo a permitir a sistematização e parametrização dos resultados. A resposta ( $\operatorname{sim}$ ) remete a conformidade legal, ou seja, a empresa está observando o previsto na legislação e possui um sistema de gestão de processamento de dados digitais adequado ao previsto na legislação. A resposta (não) remete a inconformidade, ou seja, pela simples observação do que é visível ao usuário da plataforma, os sistemas e gestão de dados digitais, possuem inconformidades e violações do previsto na legislação de proteção de dados.

O objetivo é avaliar possíveis brechas e inconformidades visíveis aos usuários das plataformas, seja na coleta e tratamento de dados de cidadãos brasileiros, seja no de cidadãos europeus. Com este método, busca-se identificar inconformidades 
LELIS. Henrique Rodrigues; COELHO, Fernando Da Cruz; LEMOS JUNIOR, Eloy Pereira. O impacto das normas de proteção de dados pessoais nos social customer relationship management. Revista Eletrônica Direito e Política, Programa de PósGraduação Stricto Sensu em Ciência Jurídica da UNIVALI, Itajaí, v.16, n.3, $3^{\circ}$ quadrimestre de 2021. Disponível em: www.univali.br/direitoepolitica - ISSN 1980-7791.

legais nos sistemas de gestão de dados, a partir do simples manuseio das plataformas digitais pelo usuário.

Não foram feitos contatos com colaboradores das empresas participantes e não foi utilizado qualquer tipo de ferramenta tecnológica para extração de dados, apenas a visualização do apresentado em tela de computador.

O quadro foi preenchido pelos próprios pesquisadores, seguindo os procedimentos abaixo:

(1) Data da coleta de dados, 20 de abril de 2020 (2) Seleção das empresas participantes seguindo os critérios acima descritos (3) A partir do site e perfil social oficial da empresa pesquisada, foram analisadas as informações lançadas de modo a obter as respostas às perguntas do quadro. (3) Perfis oficiais do Facebook são aqueles que possuem links de acesso dentro do próprio site oficial da empresa e são certificados como tais pela plataforma Facebook.

Desta forma, foi possível criar um caminho metodológico que permitiu a estruturação dos dados com critérios aplicáveis de forma igualitária a todas as empresas participantes e uma visualização racional dos resultados pelos pesquisadores.

\section{FUNDAMENTAÇÃO TEÓRICA}

O referencial teórico servirá para definição dos conceitos doutrinários e legislação aplicável ao caso, permitindo a correta interseção entre a teoria base e o estudo de caso realizado.

\subsection{Direito Digital}

O avanço da computação e digitalização dos fenômenos socioeconômicos, impactou a aplicação do Direito. Tem-se como fato que, à atualidade trouxe 
LELIS. Henrique Rodrigues; COELHO, Fernando Da Cruz; LEMOS JUNIOR, Eloy Pereira. O impacto das normas de proteção de dados pessoais nos social customer relationship management. Revista Eletrônica Direito e Política, Programa de PósGraduação Stricto Sensu em Ciência Jurídica da UNIVALI, Itajaí, v.16, n.3, $3^{0}$ quadrimestre de 2021. Disponível em: www.univali.br/direitoepolitica - ISSN 1980-7791.

consigo novas realidades que exigem adequada regulação jurídica, seja por meio da adaptação do direito já existente ao ambiente virtual, seja pela criação de novas normas jurídicas específicas ao tema.

As primeiras questões relacionadas à regulação do ambiente virtual tiveram como objeto a propriedade intelectual, mais especificamente, o trato das questões advindas da violação dos direitos autorais, marcas e patentes.

A criação e aprofundamento do uso das mídias sociais trouxe à tona novas discussões sobre o direito à intimidade e personalidade, incluindo debates sobre o direito ao esquecimento e métodos eficazes de bloqueio, controle e eliminação de dados pessoais na WEB. Em paralelo, o fenômeno da digitalização das relações comerciais provocou o surgimento e proliferação de crimes praticados a partir de plataformas digitais (crimes cibernéticos), como violação de contas bancárias, compras on-line, estelionatos, dentre outros.

Em resposta, estudiosos do direito passaram a discutir e apresentar teorias ligadas a novos campos de atuação da ciência jurídica, apontando-a como aquela que regula as relações socioeconômicas construídas e vivenciadas a partir de sistemas computacionais que operam em rede.

Em cada época de realização do estudo, a interseção Direito e Computação ganhou terminologias distintas, ou seja, diversos descritores não padronizados acabam por atuar sobre o mesmo tema e objeto de pesquisa.

Em 1979, Tunick (1979) abordou a relação entre direito e informática, dando ao tema a terminologia "Computer Law" que em tradução livre para o português perfaz "Direito dos Computadores". Para o autor, a inserção da informática na vida cotidiana impõe ao jurista a necessidade de compreensão de como é o funcionamento da máquina e de como ela é utilizada dentro da sociedade, pois, o conhecimento dos sistemas computacionais será imprescindível para o exercício do direito dentro desta nova realidade que se apresenta, já que, a massificação do uso dos computadores implicará no surgimento de inúmeros problemas legais. 
LELIS. Henrique Rodrigues; COELHO, Fernando Da Cruz; LEMOS JUNIOR, Eloy Pereira. O impacto das normas de proteção de dados pessoais nos social customer relationship management. Revista Eletrônica Direito e Política, Programa de PósGraduação Stricto Sensu em Ciência Jurídica da UNIVALI, Itajaí, v.16, n.3, $3^{\circ}$ quadrimestre de 2021. Disponível em: www.univali.br/direitoepolitica - ISSN 1980-7791.

Lopes (2013) utiliza a terminologia Direito Eletrônico, seguindo um pensamento semelhante a Peck e Leonardi quanto a sua natureza e objeto, qual seja, regulação o uso da internet.

Almeida Filho (2005) também utiliza a terminologia direito eletrônico, conceituando-o como sendo o conjunto de normas e conceitos doutrinários, destinados ao estudo e normatização de toda e qualquer relação em que a informática seja o fator primário, gerando direitos e deveres secundários a usuários ou terceiros.

De Paiva (2003) conceitua o direito eletrônico como sendo o ramo autônomo do direito que sistematiza as mais variadas normas e instituições regulamentadoras das relações sociais, estabelecidas no ambiente virtual. Este também é o pensamento de Da Silva (2006) que afirma ser o Direito eletrônico um ramo autônomo do direito, possuindo institutos, objetos, natureza jurídica e principiologia própria.

Para Lodder et al (2018), a terminologia correta é internet law ou cyber law, termo que pode ser traduzido para o português como direito da internet ou direito cibernético. Trata-se das seções de estudos e litígios jurídicos decorrentes da popularização do uso da internet. Seu campo de atuação é a regulação das atividades relacionadas ao uso da WEB, discutindo e regulando as questões relevantes a arquitetura da rede de computadores, acrescidas dos campos de direito relacionados ao seu uso pelo público, dentre eles, governança para internet, propriedade intelectual, violação de direitos fundamentais através do uso de plataformas digitais, comércio eletrônico, crimes praticados a partir de uso de plataformas digitais, segurança da informação, proteção e privacidade no uso de dados digitais.

A lei da Internet pode ser descrita brevemente como o campo jurídico em que a Internet desempenha um papel central na análise jurídica. A lei já existente, às vezes após a interpretação, é frequentemente usada para resolver problemas legais ligados à Internet. Muitas destas leis foram escritas quando a Internet não existia, ou pelo menos não da 
LELIS. Henrique Rodrigues; COELHO, Fernando Da Cruz; LEMOS JUNIOR, Eloy Pereira. O impacto das normas de proteção de dados pessoais nos social customer relationship management. Revista Eletrônica Direito e Política, Programa de PósGraduação Stricto Sensu em Ciência Jurídica da UNIVALI, Itajaí, v.16, n.3, $3^{\circ}$ quadrimestre de 2021. Disponível em: www.univali.br/direitoepolitica - ISSN 1980-7791.

maneira que existe hoje. Essas leis nunca foram destinadas à Internet, onde um único "clique" pode ter grandes consequências, atingindo facilmente uma quantidade quase infinita de pessoas. Também há novas relações sociais e jurídicas sendo criadas, especificamente para a Internet, como aquelas que lidam com spam, cookies, contratação eletrônica e cibercrime. A estrutura legal aplicável está em constante processo de desenvolvimento. Lodder et tal (2018) Tradução livre.

Cunha Guimarães e Stagni Guimarães (2017) pensam de forma complementar a Lodder. Os autores reconhecem a existência de um direito próprio voltado às relações cibernéticas, criadas a partir da popularização da internet, mas acrescentam que, a era digital configura-se pela indissociabilidade entre virtual e o físico, ou seja, o direito encontra-se agora destinado a regulamentar as novas relações sociais que surgiram com o uso da internet, não sendo possível discernir o que é aspecto virtual e físico de um ato jurídico.

Patricia Peck (2009), uma das primeiras estudiosas brasileiras sobre o tema, utiliza a terminologia Direito Digital, definindo-a como à aplicação e adaptação do direito existente aos problemas legais advindos do surgimento do ambiente o virtual, assim como, a evolução do próprio direito, com o surgimento de novos institutos e regramentos específicos a informática.

O Direito Digital nasceu da necessidade de se regularem as questões surgidas com a evolução da tecnologia e a expansão da internet, elementos responsáveis por profundas mudanças comportamentais e sociais, bem como para fazer frente aos novos dilemas da denominada "Sociedade da Informação". Pimentel (2018)

Marcelo Leonardi (2019) também utiliza este descritor, destacando que sua natureza epistemológica e transdisciplinar. Para o autor, o direito digital perfaz um sistema que integra a ciência jurídica e a ciência da computação. Em sua teoria, a arquitetura de construção da rede mundial de computadores (internet) exige uma nova abordagem jurídica, novas regulações, nova forma de ação do Estado e novas habilidades e competências do jurista no exercício da profissão. 
LELIS. Henrique Rodrigues; COELHO, Fernando Da Cruz; LEMOS JUNIOR, Eloy Pereira. O impacto das normas de proteção de dados pessoais nos social customer relationship management. Revista Eletrônica Direito e Política, Programa de PósGraduação Stricto Sensu em Ciência Jurídica da UNIVALI, Itajaí, v.16, n.3, 30 quadrimestre de 2021. Disponível em: www.univali.br/direitoepolitica - ISSN 1980-7791.

Ocorre que, para uma atuação adequada em questões jurídicas relacionadas à internet, o conhecimento de certos elementos fundamentais a respeito da rede afigura-se imprescindível, como forma de aplicar corretamente o Direito ao caso concreto. Leonardi (2019, pg. 10)

Percebe-se que a questão terminológica tem causa no fator histórico. Com o avanço da tecnologia e aprofundamento de sua aplicabilidade, os estudos mais novos apontam novos fenômenos que acabam por influenciar o uso de uma nova terminologia em detrimento de outra.

Do ponto de vista destes pesquisadores, a terminologia direito dos computadores não se adequa a abrangência do fenômeno atualmente, como também, apresenta um problema semântico, ao remeter ao estudo da máquina computacional e não as relações sociais decorrentes de massificação do uso da internet.

O direito da Internet e direito cibernético também são inadequados pela limitação do fenômeno ao uso da internet, deixando de abarcar em sua terminologia, outras questões importantes do fenômeno social como, a regulação das infra estruturas computacionais, proteção de dados, direitos da propriedade intelectual, sistemas de inteligência artificial, Machine Learning, dentre outros. Portanto, há inadequação semântica, pois direciona o pensamento para parte do objeto de estudo.

A palavra eletrônica remete ao estudo sobre o movimento e comportamento de elétrons livres, que é uma área da física e engenharia Ferreira (2012). Desta feita, o termo direito eletrônico não coaduna com o fenômeno estudado que encontrase conectado a regulação da coleta, armazenamento e tratamento de dados e informações.

A palavra digital relaciona-se com a palavra dados. Dados são sistemas de representações simbólicas de fenômenos físicos ou de um evento, uma representação formal ou descritiva da realidade, possível de ser armazenada em algum tipo de repositório, no caso computadores, para posterior quantificação e tratamento, não tendo por si, condição de oferecer significado. Davenport e Prusack (1998); Cardoso, et al (2003); Baars, et al (2015); Evangelista (2013). 
LELIS. Henrique Rodrigues; COELHO, Fernando Da Cruz; LEMOS JUNIOR, Eloy Pereira. O impacto das normas de proteção de dados pessoais nos social customer relationship management. Revista Eletrônica Direito e Política, Programa de PósGraduação Stricto Sensu em Ciência Jurídica da UNIVALI, Itajaí, v.16, n.3, $3^{\circ}$ quadrimestre de 2021. Disponível em: www.univali.br/direitoepolitica - ISSN 1980-7791.

Levando-se em consideração que todo o fenômeno relacionado ao tema tem sua origem no avanço da produção, coleta, tratamento, influência e importância do processamento de dados digitais no cotidiano da sociedade, compreendemos que o termo Direito Digital é o mais adequado para a descrição do estudo relacionado ao tema. O fenômeno base que exige nova regulação é o avanço das tecnologias de armazenamento e tratamento de dados digitais nas relações sociais, seja ele advindo do uso da internet, dos meios de comunicação pessoal, inteligência artificial ou de outros sistemas informacionais que venham a surgir, razão pela qual, o descritor direito digital encontra-se terminologicamente mais adequado ao tema.

O campo de atuação do Direito Digital subdivide-se em dois: O primeiro é a regulação da arquitetura dos sistemas computacionais de coleta, armazenamento e processamento de dados digitais, especialmente, os advindos da rede mundial de computadores; o segundo, regula o impacto do uso de dados digitais no cotidiano social, incluindo a solução de conflitos legais relacionados a sua massificação.

O direito é um sistema único, interdisciplinar e interdependente, formando um mosaico único e indivisível. Sua subdivisão em áreas especiais nada mais é que uma forma de simplificação de seu estudo e aprendizado, não possuindo efeito sobre sua aplicabilidade ao caso concreto. Desta forma, o debate sobre a autonomia do direito digital é irrelevante para esta pesquisa, bastando a compreensão de sua teoria base, características e fenômeno social que o provocou.

Em síntese, para fins aplicáveis a este estudo de caso, define-se direito digital como sendo o estudo da legislação, doutrina e jurisprudência aplicável ao sistemas de gestão e processamento de dados e informações digitais, incluindo a regulação jurídica da arquitetura da rede mundial de computadores, gestão de banco de dados dados digitais e os impactos do uso dos sistemas de informação no cotidiano da sociedade. 
LELIS. Henrique Rodrigues; COELHO, Fernando Da Cruz; LEMOS JUNIOR, Eloy Pereira. O impacto das normas de proteção de dados pessoais nos social customer relationship management. Revista Eletrônica Direito e Política, Programa de PósGraduação Stricto Sensu em Ciência Jurídica da UNIVALI, Itajaí, v.16, n.3, $3^{\circ}$ quadrimestre de 2021. Disponível em: www.univali.br/direitoepolitica - ISSN 1980-7791.

\subsection{Lei Geral de Proteção de Dados}

A questão relacionada à regulação da proteção da privacidade e intimidade da pessoa é antiga, tendo sua primeira aparição nos EUA no ano de 1890, com o debate sobre o uso exacerbado da fotografia por tabloides jornalísticos. Com a promulgação da Declaração Universal dos Direitos Humanos, reconhece-se o direito à privacidade e intimidade como direito humano. Em 1970, no Estado de Hesse, na Alemanha, surge a primeira legislação reguladora da proteção de dados pessoais, na qual há, expressamente, uma vinculação dos dados pessoais à intimidade e privacidade do cidadão. Maciel (2019)

Com o avanço das tecnologias de processamento de dados e da rede mundial de computadores, inúmeras legislações foram sendo promulgadas ao longo dos últimos anos, destacando-se, no contexto mundial, como a mais recente é a mais impactante, a General Data Protection Regulation (GDPR), norma aprovada e aplicada pela União Europeia para proteção de dados pessoais de cidadãos que vivem dentro do bloco econômico.

A lei europeia aplica-se tanto às organizações instaladas dentro do bloco como também, aquelas que realizam transações comerciais com estas, mesmo que as empresas encarregadas da gestão de bancos de dados estejam instaladas em

países fora da União Europeia. Assim, empresas instaladas em países que não possuem legislação reguladora da proteção de dados pessoais, estarão impedidas de transacionar com organizações pertencentes à União Europeia, pois, o compartilhamento de dados pessoais a partir de seus banco de dados, violaria normas impostas pela GDPR.

Desta feita, o governo brasileiro viu-se obrigado a realizar adequações legislativas para proteção de dados pessoais, de modo a conferir legalidade ao tratamento de dados pessoais dentro do território nacional brasileiro, permitindo a continuidade das relações comerciais existentes entre a atividade produtiva nacional e o bloco econômico europeu. Maciel (2019); Peck (2020). 
LELIS. Henrique Rodrigues; COELHO, Fernando Da Cruz; LEMOS JUNIOR, Eloy Pereira. O impacto das normas de proteção de dados pessoais nos social customer relationship management. Revista Eletrônica Direito e Política, Programa de PósGraduação Stricto Sensu em Ciência Jurídica da UNIVALI, Itajaí, v.16, n.3, $3^{\circ}$ quadrimestre de 2021. Disponível em: www.univali.br/direitoepolitica - ISSN 1980-7791.

No dia 14 de agosto de 2018 foi promulgada a lei 13.709, denominada lei geral de proteção de dados. Seu objeto é a proteção à intimidade, privacidade e personalidade do cidadão frente ao crescente uso de sistemas de gestão e tratamento de dados pessoais. Para tal fim, ela regulamenta a forma de coleta, armazenamento e tratamento de dados pessoais.

Sua finalidade é a busca do equilíbrio entre o desenvolvimento da economia pautada na gestão do conhecimento e informação e a proteção ao direito fundamental à privacidade e à personalidade de cada cidadão. Maciel (2019).

A lei geral de proteção de dados possui natureza jurídica de direito fundamental, pois sua finalidade é a proteção à privacidade e à personalidade do cidadão. Encontra-se como típica norma do direito digital, regulamentando formas de gestão de banco de dados digitais, solucionando problemas legais advindos de uso massificado de dados digitais. Encontra-se também relacionada a regulação do risco, pautando-se na ideia de estrutura legal que regula, controla e mitiga riscos, severidades e probabilidade de danos coletivos.

No modelo tipológico da regulação do risco, a proteção de dados pessoais "risquificada" passa a ter os seguintes elementos: (i) instrumentos de tutela coletiva e participação de entidades civis no diálogo preventivo com autoridades independentes de proteção de dados pessoais, (ii) obrigações e instrumentos de regulação atribuídas aos controladores para identificação de riscos a direitos e liberdades fundamentais, (iii) disseminação de metodologias de "gestão de risco" e calibragem entre riscos gerados pelo tratamento e uso de dados pessoais e imunidades jurídicas construídas pela discussão ética sobre os limites do progresso técnico. Zanata (2017)

De sua estrutura normativa destaca-se quatro constructos a serem efetivados: A clareza da informação, a partir de parâmetros legais que obrigam encarregados e controladores de bancos de dados a informarem ao cidadão, de forma clara e objetiva, quais dados estão sendo coletados, como estão sendo tratados e para quais finalidades; O controle dos dados, dando ao cidadão condição de exercer seu direito de acessar, retificar, supervisionar, contestar e apagar os dados pessoais 
LELIS. Henrique Rodrigues; COELHO, Fernando Da Cruz; LEMOS JUNIOR, Eloy Pereira. O impacto das normas de proteção de dados pessoais nos social customer relationship management. Revista Eletrônica Direito e Política, Programa de PósGraduação Stricto Sensu em Ciência Jurídica da UNIVALI, Itajaí, v.16, n.3, $3^{0}$ quadrimestre de 2021. Disponível em: www.univali.br/direitoepolitica - ISSN 1980-7791.

tratados incorretamente; A prevenção, com normas legais que obrigam o desenvolvimento de sistemas de gestão de dados que sejam eficazes no controle e prevenção de possíveis vazamentos e uso indevido de dados pessoais; A Mitigação, que trabalha na lógica de redução dos riscos de danos e consequências, no caso de uso inadequado dos dados pessoais.

A lei entrou em vigor no dia 28 de dezembro de 2018 de forma parcial, prevendo a aplicação total de suas determinações a partir de 1 de janeiro de 2021.

\subsection{General Data Protection Regulation (GDPR)}

O General Data Protection Regulation (GDPR), em tradução livre para o português "Regulamento Geral de Proteção de Dados (RGPD), foi aprovada no ano de 2016, com vigência desde 2018, aplicando-se a todas as organizações e indivíduos situadas dentro dos territórios dos países membros, como também, a todos os sistemas de gestão de dados que exportam dados pessoais de cidadãos da União Europeia.

Seu objetivo é regulamentar a forma de tratamento e a circulação de dados pessoais, de maneira a defender os direitos e liberdades das pessoas singulares, especialmente os vinculados à intimidade e personalidade frente a fenômenos como Big Data, globalização da economia e modelos de negócios pautados em gestão do conhecimento. Azurmendi (2018)

O GDPR é um sistema jurídico que fornece proteção dos interesses dos cidadãos europeus quando do processo de dados pessoais, bem como, cria um marco legal orientador de como deve ser a feita a gestão de sistemas de dados e informação para propósitos legítimos, criando critérios e maneiras pelas quais as organizações coletam, tratam e compartilham dados pessoais. Dove (2018)

Sua aplicação perfaz qualquer sistema de gestão de dados que coleta e trata dados pessoais de cidadãos europeus, independente da localização territorial do controlador do sistema de gestão de dados. Assim, organizações que pretendem 
LELIS. Henrique Rodrigues; COELHO, Fernando Da Cruz; LEMOS JUNIOR, Eloy Pereira. O impacto das normas de proteção de dados pessoais nos social customer relationship management. Revista Eletrônica Direito e Política, Programa de PósGraduação Stricto Sensu em Ciência Jurídica da UNIVALI, Itajaí, v.16, n.3, $3^{\circ}$ quadrimestre de 2021. Disponível em: www.univali.br/direitoepolitica - ISSN 1980-7791.

operar negócios com o mercado europeu, são obrigadas a respeitar esta legislação, mesmo estando localizadas em territórios de Estados não membros. Piper (2019); Veritas Technologies (2016)

Como resultado, organizações brasileiras que realizam ou pretendem realizar negócios no âmbito da União Europeia, são obrigadas a adequar seus sistemas de gestão de dados a esta normativa, pois, a inconformidade implicará na recusa dos gestores europeus de realizar qualquer tratativa comercial, face às responsabilidades impostas pela GDPR.

\subsection{Conceito de Mídia Social}

Yawised, Ellis e Wong (2018) define Mídia Social como sendo as tecnologias usadas na WEB para fins sociais. Trata-se de modos de interação social entre usuários, a partir de aplicativos e sites de redes sociais.

Siriwardana e Dissanayake (2018) compreende o termo como sendo as plataformas de comunicação digital entre usuários, destacando a sua importância para a conexão entre as organizações e seus consumidores.

Para Reinhold, Alt (2019) as mídias sociais podem ser definidas como a comunicação baseada na Web, especialmente, a partir de aplicativos que permitem a criação, acesso e troca de conteúdo gerado pelo usuário.

Mídias Sociais são ferramentas comumente referidas como WEB 2.0 ou computação social. Trata-se de aplicativos da WEB que promovem a interação e compartilhamento de informações por usuários, a partir de sistemas que possuem design centralizado nestes. Malhorta (2018).

Boyd e Ellison (2007) compreende o termo sites de Redes Sociais como serviços baseados na Web que permitem aos indivíduos construírem um perfil público ou semipúblico, dentro de uma plataforma digital específica, criando e articulando, por sua própria iniciativa, uma lista de outros usuários com quem compartilham 
LELIS. Henrique Rodrigues; COELHO, Fernando Da Cruz; LEMOS JUNIOR, Eloy Pereira. O impacto das normas de proteção de dados pessoais nos social customer relationship management. Revista Eletrônica Direito e Política, Programa de PósGraduação Stricto Sensu em Ciência Jurídica da UNIVALI, Itajaí, v.16, n.3, $3^{\circ}$ quadrimestre de 2021. Disponível em: www.univali.br/direitoepolitica - ISSN 1980-7791.

uma conexão, visualizando mutuamente, sua lista de conexões ou as feitas por outras pessoas do sistema.

Sites de redes sociais refletem estruturas sociais construídas e modificadas pelos atores, através das ferramentas de comunicação proporcionadas pelos sistemas, incluindo-se aí o aparecimento das redes sociais, aqui compreendidas como grupos de indivíduos (atores) cujas trocas conversacionais vão gerar laços e capital social. Nesses espaços, são construídas conversações síncronas e assíncronas que têm diferentes efeitos sobre a estrutura da rede social (Recuero, 2009).

Em síntese, o conceito de Mídia Social pode ser compreendido como as aplicações para internet, também conhecida como WEB 2.0, cujo o propósito é promover a interação social entre usuários, permitindo a estes produzir, compartilhar e acessar os mais diversos conteúdos informacionais de forma autônoma e independente, como também, permitem a comunicação direta entre estes usuários de forma sincrônica ou assincrônica.

\subsection{Gestão da Informação, Inteligência Competitiva e tratamento de dados pessoais}

A discussão sobre a importância da gestão da informação e do conhecimento se desenvolveu ao longo da segunda metade do século XX. A questão suscitada deita causa na preocupação quanto ao excesso de dados e informações gerados e armazenados pelos novos sistemas tecnológicos da informação, que acabam por provocar dificuldades no processo decisório. Em complemento, tem-se a crescente importância do próprio conhecimento e capital intelectual como diferencial competitivo das organizações empresariais, o que levou à ampliação dos estudos relacionados ao tema. Barbosa (2008)

Levando-se em conta o contexto destas transformações, salienta-se a necessidade de uma atenção focalizada no gerenciamento dos processos relacionados à obtenção, circulação e uso informação e do conhecimento, especialmente quando 
LELIS. Henrique Rodrigues; COELHO, Fernando Da Cruz; LEMOS JUNIOR, Eloy Pereira. O impacto das normas de proteção de dados pessoais nos social customer relationship management. Revista Eletrônica Direito e Política, Programa de PósGraduação Stricto Sensu em Ciência Jurídica da UNIVALI, Itajaí, v.16, n.3, $3^{\circ}$ quadrimestre de 2021. Disponível em: www.univali.br/direitoepolitica - ISSN 1980-7791.

da tomada de decisão. Para que esse gerenciamento seja efetivo é necessário o desenvolvimento de uma forma de olhar a organização sob o prisma da informação e do conhecimento, sendo este o objeto dos sistemas de informação e gestão do conhecimento. Barbosa (2008)

Valetim (2002) conceitua a gestão da informação como processo de gerenciamento dos fluxos informacionais, formais ou informais, necessários para o exercício das atividades dentro da organização. Trata-se de ações integradas visando a prospecção, seleção, filtro, tratamento e disseminação do ativo informacional e intelectual da organização, incluindo desde documentos, bancos de dados, até conhecimentos individuais produzidos por atores existentes externamente à organização.

É importante salientar que os fluxos informacionais formais e informais ocorrem tanto no ambiente interno quanto no ambiente externo à organização e as ações integradas mencionadas no parágrafo anterior devem ser realizadas nos dois ambientes. Desta maneira, argumenta-se a importância da organização definir em seu organograma uma unidade de trabalho especificamente voltada a desenvolver ações e atividades à gestão da informação, gestão do conhecimento ou inteligência competitiva na organização. (valetim (2002)

Para Monteiro e Falsarella (2007), a Gestão da Informação consiste no conjunto de atividades voltadas à informação, como busca, obtenção, tratamento, agregação de valor, armazenamento, disponibilização, uso e retroalimentação.

Trata-se, portanto, de um processo cíclico. Assim, podemos falar em um ciclo da gestão da informação o qual parte de uma demanda por informação que conduz a uma busca. Por sua vez a busca gera uma obtenção (informação recuperada). A informação obtida ou é armazenada ou é tratada, ou seja, contextualizada e é agregado valor para em seguida ser armazenada. Esta informação tratada e/ou armazenada fica à disposição para uso. O uso produz novas informações ou gera necessidade de mais informações, recomeçando o ciclo. Monteiro; Falsarella (2007)

Silva et al (2001) utiliza a terminologia Sistema de Informação Estratégica (SIE), destacando o seu propósito que é organizar, disponibilizar e analisar informações 
LELIS. Henrique Rodrigues; COELHO, Fernando Da Cruz; LEMOS JUNIOR, Eloy Pereira. O impacto das normas de proteção de dados pessoais nos social customer relationship management. Revista Eletrônica Direito e Política, Programa de PósGraduação Stricto Sensu em Ciência Jurídica da UNIVALI, Itajaí, v.16, n.3, $3^{\circ}$ quadrimestre de 2021. Disponível em: www.univali.br/direitoepolitica - ISSN 1980-7791.

estratégicas e táticas. A SIE atua no ambiente interno, contribuindo com a melhoria do fluxo informacional e maior integração das áreas, permitindo um melhor ambiente de compartilhamento e renovação. No ambiente externo, o SIE contribui com as relações de parcerias e visualização de tendências, por meio do monitoramento de mercado, tecnologias, competências, políticas e outros fatores chaves. Tudo com foco na identificação de oportunidades, descoberta de soluções para problemas, criação e manutenção de vantagens competitivas.

No que tange ao conceito de Inteligência Competitiva, Marques e Vidigal (2018) o define como um processo institucional, composto por planejamento, coleta, análise e disseminação de informações, transformadas em inteligência, que amparam os gestores, de forma eficiente e eficaz, em seus processos decisórios.

Rajan (2009) o apresenta como sendo um conjunto de metodologias e tecnologias voltadas para a melhoria das operações da empresa, especialmente, aquelas ligadas ao apoio na tomada de decisão.

Foley; Guillemette (2010) chamam atenção para a profusão de conceitos e terminologias sobre o tema, o que resultam em ambiguidades e dificuldades de desenvolvimento da temática. Pirttimäki (2007) também questiona o uso de terminologias distintas para definição do mesmo fenômeno. Ele a descreve como sendo um processo sistemático de atividades dentro da organização, voltadas para o atendimento das necessidades específicas de informação dos tomadores de decisão, cujo objetivo é alcançar vantagens competitivas.

Fuld (2002) elenca 10 características do que se pode chamar de Inteligência Competitiva: (1) Informações que foram analisadas até o ponto em que você pode tomar uma decisão; (2) Uma ferramenta para alertar a gerência de forma antecipada sobre ameaças e oportunidades; (3) Um meio para fornecer informações consistentes e razoáveis; (4) É desenvolvida de várias formas; (5) Uma maneira das empresas melhorarem seus resultados; (6) Um processo perene e permanente dentro da organização; (7) Parte integrante de todas as melhores 
LELIS. Henrique Rodrigues; COELHO, Fernando Da Cruz; LEMOS JUNIOR, Eloy Pereira. O impacto das normas de proteção de dados pessoais nos social customer relationship management. Revista Eletrônica Direito e Política, Programa de PósGraduação Stricto Sensu em Ciência Jurídica da UNIVALI, Itajaí, v.16, n.3, $3^{\circ}$ quadrimestre de 2021. Disponível em: www.univali.br/direitoepolitica - ISSN 1980-7791.

empresas do setor; (8) Incentivado e dirigido pela diretoria executiva; (9) Uma visão externa da organização (10) Usada tanto no curto como a longo prazo.

Neste sentido, a Gestão da Informação e Inteligência Competitiva são conceitos correlatos, diretamente relacionados à coleta, armazenamento e tratamento de dados e informações, transformados em conhecimento organizacional, com propósito de obtenção e manutenção de vantagem competitiva.

Portanto, a Lei Geral de Proteção de dados Pessoais, impacta os modelos teóricos ou práticos relacionados a estes conceitos, pois, sistemas de informação, gestão do conhecimento e inteligência competitiva, certamente se servirão da coleta, armazenamento e tratamento de dados de clientes, fornecedores e colaboradores, para construção de relatórios focados na busca por inovação e vantagem competitiva.

\subsection{Conceito de Social Customer Relationship Management}

O Social Customer Relationship Management é um conceito de pesquisa relativamente recente. Apesar da influência das Mídias Sociais nas estratégias de Marketing de Relacionamento e de gestão da informação já serem discutidas a longos anos, a defesa de um novo sistema construído de forma integrada as mídias sociais, utilizando ferramentas e modelos próprios para coleta e tratamento de dados digitais advindos das plataformas de mídias sociais tem início recente.

A força e importância adquirida pelas mídias sociais, alinhadas a falta de informações objetivas sobre os efeitos da digitalização nos negócios, perfizeram os fatores para o desenvolvimento da temática, mais especificamente, destacase: (1) forte aumento do uso das mídias sociais pela sociedade em geral. (2) ampliação e aprimoramento das tecnologias da informação que possibilitam o uso das plataformas de mídias sociais como forma de vantagem competitiva. (3) ampliação do E-commerce e uso do WEB para criação de novos produtos, serviços e aprimoramento dos já existentes. (4) Difusão de modelos de gestão do 
LELIS. Henrique Rodrigues; COELHO, Fernando Da Cruz; LEMOS JUNIOR, Eloy Pereira. O impacto das normas de proteção de dados pessoais nos social customer relationship management. Revista Eletrônica Direito e Política, Programa de PósGraduação Stricto Sensu em Ciência Jurídica da UNIVALI, Itajaí, v.16, n.3, $3^{\circ}$ quadrimestre de 2021. Disponível em: www.univali.br/direitoepolitica - ISSN 1980-7791.

conhecimento, da informação e inteligência competitiva e o destaque destes como estratégicos para as organizações.

Portanto, o conceito de Social Customer Relationship management surge como consequência dos debates sobre os impactos das Mídias Sociais no Marketing de Relacionamento e CRM, perfazendo o entendimento de que, esta influência, exige um novo modelo de gestão organizacional.

Social Customer Relationship Management, também conhecido como Social-CRM ou CRM 2.0, é uma metodologia de gestão empresarial reforçada pela tecnologia e princípios de negócios, cujo foco é atrair o cliente para uma discussão comunitária engajada sobre bens e serviços da organização. Seu objetivo é criar laços de credibilidade e confiabilidade entre marca e cliente, possibilitando a construção de uma condição comercial favorável. (Greenber, 2009)

O Social CRM é a estratégia de negócios de atrair clientes através das mídias sociais com o objetivo de criar confiança e fidelidade à marca. Lealdade é definida como atitude em relação a uma marca que inclina um cliente a recomprá-la e/ou recomendá-la a outros. Social CRM e Social Media têm mais a ver com criar confiança e gerenciar lealdade com os clientes, do que sobre gerenciar transações comerciais, que são áreas de foco do CRM "tradicional". (Kotadia,2009, tradução nossa)

Os modelos de gestão Social-CRM se diferenciam do CRM tradicional na medida que, no primeiro, busca-se o crescimento da marca a partir do empoderamento e engajamento do cliente. O Social-CRM disponibiliza e utiliza ferramentas tecnológicas para coletar e tratar dados digitais, advindos de plataformas de mídias sociais, visando desenvolver um relacionamento com os clientes da organização. Seu propósito é propiciar um ambiente virtual que permita o usuário da plataforma, usufruir de produtos, serviços e experiências a partir da interatividade. Ou seja, é o cliente o principal criador e difusor de conteúdos promotores do desenvolvimento e crescimento da marca.

Isso significa que a empresa está disposta a ser transparente o suficiente e honesta o suficiente (segue o atualmente "autêntico") para ser confiável por esse cliente. Então, a 
LELIS. Henrique Rodrigues; COELHO, Fernando Da Cruz; LEMOS JUNIOR, Eloy Pereira. O impacto das normas de proteção de dados pessoais nos social customer relationship management. Revista Eletrônica Direito e Política, Programa de PósGraduação Stricto Sensu em Ciência Jurídica da UNIVALI, Itajaí, v.16, n.3, $3^{\circ}$ quadrimestre de 2021. Disponível em: www.univali.br/direitoepolitica - ISSN 1980-7791.

empresa se torna uma empresa como eu". A experiência que o cliente tem com a empresa é positiva o suficiente para transformá-lo em pelo menos leal e, na melhor das hipóteses, um advogado. (Mosadegh, Behboudi, 2011, tradução nossa)

O Social-CRM tem fulcro na busca de modelos de gestão que proporcionem vantagem competitiva pela organização, quando do trato com cliente que utiliza a mídia social para procurar, comparar e contrastar os produtos e serviços oferecidos. Ela também serve ao propósito de coletar, tratar e gerenciar dados e informações criadas e difundidas na WEB sobre a organização, seus produtos e sobre o mercado de atuação. No Social-CRM estão inclusos o desenvolvimento de ferramentas de programação social (análise de dados, Machine Learning e inteligência artificial) que sejam capazes de reagir rapidamente a perguntas e questionamentos do interesse do cliente, frente a organização no ambiente da WEB. (Siriwardana, Dissanayake, 2018)

A criação de conteúdos que satisfaçam o consumidor poderá, assim, ser otimizada pela panóplia de conhecimento que a tecnologia permite. No novo capítulo do marketing (de conteúdos), o Social-CRM apresenta-se como uma ferramenta privilegiada de informação e como o melhor suporte estratégico para a criação de relações de sucesso entre o cliente e a marca. É pura matemática: mais conhecimento, melhores conteúdos, cliente satisfeito. (Marques; Costa, 2018)

A questão relacionada ao Social-CRM, envolve diretamente a forma pela qual a organização trata dados pessoais, pois a teoria base que o sustenta as ferramentas tecnológicas aplicadas em sua gestão, dependem da coleta e tratamento de dados digitais, o que, a partir da vigência da nova legislação, exige uma análise quanto à conformidade legal desses sistemas frente aos preceitos legais.

Sistemas de Social-CRM e legislação de proteção de dados pessoais formam um mosaico indivisível. Decisões e operações tomadas dentro da ótica do Social-CRM, surtem efeitos legais, obrigando os controladores a refazerem seus processos internos para detectar, contornar ou corrigir inconformidades legais ou de conduta. Por sua vez, a inconformidade legal não detectada ou ignorada, causará danos à 
LELIS. Henrique Rodrigues; COELHO, Fernando Da Cruz; LEMOS JUNIOR, Eloy Pereira. O impacto das normas de proteção de dados pessoais nos social customer relationship management. Revista Eletrônica Direito e Política, Programa de PósGraduação Stricto Sensu em Ciência Jurídica da UNIVALI, Itajaí, v.16, n.3, $3^{\circ}$ quadrimestre de 2021. Disponível em: www.univali.br/direitoepolitica - ISSN 1980-7791.

organização, seja por meio das penalidades legais ou pela perda de credibilidade e valor de mercado da marca.

Sendo assim, estudos transdisciplinares, com avaliações de impacto da nova lei de dados, sob a ótica Social-CRM e compliance digital, irão contribuir para o amadurecimento, tanto das teorias ligadas ao marketing, como para as teorias jurídicas, na medida que, permitem uma visualização de um problema jurídico concreto.

\section{BREVE RESUMO DAS EMPRESAS}

No quadro abaixo, apresenta-se o perfil econômico das empresas estudadas. O objetivo é descrever a estrutura empresarial, para a correta interpretação dos dados para fins acadêmicos. A denominação social e outros elementos identificadores da marca foram ocultados, por serem irrelevantes para os fins que se almejam.

\begin{tabular}{|c|c|c|c|c|c|}
\hline $\begin{array}{c}\text { Emp. } \\
\text { Brasileiras }\end{array}$ & $\begin{array}{l}\text { Ano de } \\
\text { Fundação }\end{array}$ & $\begin{array}{l}\text { Localização da } \\
\text { matriz }\end{array}$ & $\begin{array}{c}\text { Principal } \\
\text { produto } \\
\text { comercializado }\end{array}$ & $\begin{array}{c}\text { Realiza } \\
\text { exportação } \\
\text { de produtos }\end{array}$ & $\begin{array}{c}\text { Possui Marca } \\
\text { global } \\
\text { (mais de } 40 \\
\text { países) }\end{array}$ \\
\hline Zeta & 1951 & São Paulo & Bebida alcoólica & $\operatorname{sim}$ & não \\
\hline Kappa & 1944 & Santa Catarina & $\begin{array}{c}\text { Carnes e } \\
\text { embutidos }\end{array}$ & $\operatorname{sim}$ & $\operatorname{sim}$ \\
\hline Alpha & 1952 & São Paulo & $\begin{array}{c}\text { Pães, Bolos e } \\
\text { Biscoitos }\end{array}$ & $\operatorname{sim}$ & não \\
\hline Beta & 2009 & Minas Gerais & Chocolates & não & não \\
\hline Gama & 1988 & São Paulo & Chocolates & não & não \\
\hline $\begin{array}{c}\text { Emp. } \\
\text { Europeias }\end{array}$ & $\begin{array}{c}\text { Ano de } \\
\text { Fundação }\end{array}$ & $\begin{array}{c}\text { Localização da } \\
\text { matriz }\end{array}$ & $\begin{array}{c}\text { Principal } \\
\text { produto } \\
\text { comercializado }\end{array}$ & \begin{tabular}{l}
\multicolumn{1}{c}{ Realiza } \\
exportação \\
de produtos
\end{tabular} & $\begin{array}{c}\text { Possui Marca } \\
\text { global } \\
\text { (mais de } 40 \\
\text { países) }\end{array}$ \\
\hline Delta & 1866 & Suíça & $\begin{array}{l}\text { Alimentos } \\
\text { diversos }\end{array}$ & Sim & $\operatorname{sim}$ \\
\hline Sigma & 1942 & Itália & Chocolates & Sim & $\operatorname{sim}$ \\
\hline Ômega & 1900 & Holanda & Balas e doces & Sim & $\operatorname{sim}$ \\
\hline
\end{tabular}

Comparando as empresas brasileiras com as europeias, a maior diferença está na internacionalização dos negócios. As empresas europeias possuem atuação 
LELIS. Henrique Rodrigues; COELHO, Fernando Da Cruz; LEMOS JUNIOR, Eloy Pereira. O impacto das normas de proteção de dados pessoais nos social customer relationship management. Revista Eletrônica Direito e Política, Programa de PósGraduação Stricto Sensu em Ciência Jurídica da UNIVALI, Itajaí, v.16, n.3, $3^{\circ}$ quadrimestre de 2021. Disponível em: www.univali.br/direitoepolitica - ISSN 1980-7791.

internacional maior, exportando seus produtos a diversos países, com marcas e produtos conhecidos e comercializados em âmbito global, incluindo participação em mercados consumidores de países latino americanos, asiáticos e da Oceania. Por sua vez, as empresas brasileiras estão focadas no comercio nacional, com marcas e produtos pouco trabalhados no âmbito internacional. Apenas duas empresas são exportadoras e apenas uma possui atuação global.

Outro ponto relevante para esta pesquisa, está nos dados extraídos da pagina oficial do Facebook de cada empresa, conforme descrito na tabela abaixo.

\begin{tabular}{|c|c|c|c|c|c|}
\hline $\begin{array}{l}\text { Emp. } \\
\text { Brasileira } \\
\quad \mathrm{s}\end{array}$ & $\begin{array}{c}\text { Principal } \\
\text { Finalidade das } \\
\text { Plat. digitais }\end{array}$ & $\begin{array}{c}\text { Utiliza Plat. } \\
\text { digitais para } \\
\text { venda direta ao } \\
\text { consumidor }\end{array}$ & $\begin{array}{c}\text { Transparência } \\
\text { na Página do } \\
\text { Facebook }\end{array}$ & $\begin{array}{c}\text { Seguidores } \\
\text { no Facebook }\end{array}$ & $\begin{array}{c}\text { Comentários } \\
\text { nos } 3 \text { primeiros } \\
\text { post's }\end{array}$ \\
\hline Zeta & $\begin{array}{l}\text { Engajamento e } \\
\text { Relacionamento } \\
\text { com público alvo }\end{array}$ & Não & Criada em 2010 & $1,189,825$ & $\begin{array}{c}47 \text { comentários } \\
105 \\
\text { compartilhamentos } \\
350 \text { curtidas }\end{array}$ \\
\hline Kappa & $\begin{array}{c}\text { Engajamento e } \\
\text { Relacionamento } \\
\text { com público alvo }\end{array}$ & Não & $\begin{array}{l}\text { Não preenchida } \\
\text { pela empresa }\end{array}$ & $3,714,860$ & $\begin{array}{c}246.500 \text { comentários } \\
4.473 \text { compart. } \\
2.409 \text { curtidas } \\
\end{array}$ \\
\hline Alpha & $\begin{array}{l}\text { Engajamento e } \\
\text { Relacionamento } \\
\text { com público alvo }\end{array}$ & Link desativado & $\begin{array}{l}\text { Criada em } \\
2016\end{array}$ & 407,845 & $\begin{array}{c}155 \text { comentários } \\
12 \\
\text { compartilhamentos } \\
2.061 \text { curtidas }\end{array}$ \\
\hline Beta & $\begin{array}{l}\text { Engajamento e } \\
\text { Relacionamento } \\
\text { com público alvo }\end{array}$ & Não & $\begin{array}{l}\text { Não preenchida } \\
\text { pela empresa }\end{array}$ & $3,140,474$ & $\begin{array}{c}688 \text { comentários } \\
163 \\
\text { compartilhamentos } \\
1.425 \text { curtidas }\end{array}$ \\
\hline Gama & $\begin{array}{l}\text { Engajamento e } \\
\text { Relacionamento } \\
\text { com público alvo }\end{array}$ & Link desativado & $\begin{array}{l}\text { Não preenchida } \\
\text { pela empresa }\end{array}$ & $9,767,192$ & $\begin{array}{c}8.400 \text { Comentários } \\
631 \\
\text { compartilhamentos } \\
7.200 \text { curtidas } \\
\end{array}$ \\
\hline $\begin{array}{l}\text { Emp. } \\
\text { Europeia } \\
\quad \mathrm{s} \\
\end{array}$ & $\begin{array}{c}\text { Principal } \\
\text { Finalidade } \\
\text { das Plat. digitais }\end{array}$ & $\begin{array}{c}\text { Utiliza Plat. } \\
\text { digitais para } \\
\text { venda direta ao } \\
\text { consumidor } \\
\end{array}$ & $\begin{array}{c}\text { Transparência } \\
\text { na Página do } \\
\text { Facebook }\end{array}$ & $\begin{array}{c}\text { Seguidores } \\
\text { no Facebook }\end{array}$ & $\begin{array}{c}\text { Comentários } \\
\text { nos } 3 \text { primeiros } \\
\text { post's }\end{array}$ \\
\hline Delta & $\begin{array}{l}\text { Engajamento e } \\
\text { Relacionamento } \\
\text { com público alvo }\end{array}$ & Não & Criada em 2012 & $11,461,567$ & $\begin{array}{c}16 \text { Comentários } \\
28 \\
\text { compartilhamentos } \\
400 \text { curtidas }\end{array}$ \\
\hline Sigma & $\begin{array}{l}\text { Engajamento e } \\
\text { Relacionamento } \\
\text { com público alvo }\end{array}$ & Não & $\begin{array}{l}\text { Criada em } \\
2016\end{array}$ & $20,351,975$ & $\begin{array}{c}28 \text { Comentários } \\
32 \\
\text { compartilhamentos } \\
164 \text { curtidas }\end{array}$ \\
\hline Omega & $\begin{array}{l}\text { Engajamento e } \\
\text { Relacionamento } \\
\text { com público alvo }\end{array}$ & Não & Criada em 2011 & $12,890,511$ & $\begin{array}{c}\text { 1.300 Comentários } \\
721 \\
\text { compartilhamentos } \\
9.200 \text { curtidas }\end{array}$ \\
\hline
\end{tabular}


LELIS. Henrique Rodrigues; COELHO, Fernando Da Cruz; LEMOS JUNIOR, Eloy Pereira. O impacto das normas de proteção de dados pessoais nos social customer relationship management. Revista Eletrônica Direito e Política, Programa de PósGraduação Stricto Sensu em Ciência Jurídica da UNIVALI, Itajaí, v.16, n.3, $3^{\circ}$ quadrimestre de 2021. Disponível em: www.univali.br/direitoepolitica - ISSN 1980-7791.

Todas as empresas pesquisadas possuem amplo engajamento em mídias sociais, incluindo comentários, curtidas e compartilhamento de posts, em ordem de grandeza de na casa de milhões de seguidores, tanto para empresas brasileiras como europeias.

Levando-se em consideração que um aspecto importante do Social-CRM é a mineração de dados digitais, com posterior cruzamento com aqueles extraídos das mídias sociais e de outras fontes, formando um sistema estruturado de informação que posteriormente será utilizado pela gestão empresarial na tomada de decisão estratégica, a questão relacionada a autorização para coleta e tratamento de dados pessoais, compartilhamento entre controladores diversos e principalmente, garantia de informação ao consumidor/cidadão quanto a forma e objetivo do uso dos dados pessoais coletados são fundamentais.

\section{ANÁLISE E DISCUSSÃO DOS DADOS}

Aplicando-se o quadro questionário desenvolvido, nos termos do caminho metodológico já apresentado, foram obtidos os seguintes resultados.

\begin{tabular}{|c|c|c|c|c|c|c|c|c|c|c|}
\hline $\begin{array}{c}\text { Empresas } \\
\text { brasileiras }\end{array}$ & $\begin{array}{l}\text { Per } \\
\text { g. } \\
\text { 01 }\end{array}$ & $\begin{array}{l}\text { Per } \\
\text { g. } \\
\text { 02 }\end{array}$ & $\begin{array}{l}\text { Per } \\
\text { g. } \\
03\end{array}$ & $\begin{array}{l}\text { Per } \\
\text { g. } \\
\text { 04 }\end{array}$ & $\begin{array}{l}\text { Per } \\
\text { g. } \\
\text { 05 }\end{array}$ & $\begin{array}{l}\text { Per } \\
\text { g. } \\
06\end{array}$ & $\begin{array}{l}\text { Per } \\
\text { g. } \\
07\end{array}$ & $\begin{array}{l}\text { Per } \\
\text { g. } \\
08\end{array}$ & $\begin{array}{l}\text { Per } \\
\text { g. } \\
09\end{array}$ & $\begin{array}{c}\text { conformidade } \\
\text { com as leis de } \\
\text { dados }\end{array}$ \\
\hline 1.Zeta & & & & & & & & & & \\
\hline 2. Карра & & & & & & & & & & \\
\hline 3. Alpha & & & & & & & & & & \\
\hline 4. Beta & & & & & & & & & & \\
\hline 5. Gama & & & & & & & & & & \\
\hline $\begin{array}{l}\text { Empresas } \\
\text { europeias }\end{array}$ & $\begin{array}{l}\text { Per } \\
\text { g. } \\
\text { 01 }\end{array}$ & $\begin{array}{l}\text { Per } \\
\text { g. } \\
02\end{array}$ & $\begin{array}{l}\text { Per } \\
\text { g. } \\
03\end{array}$ & $\begin{array}{l}\text { Per } \\
\text { g. } \\
\text { 04 }\end{array}$ & $\begin{array}{l}\text { Per } \\
\text { g. } \\
05\end{array}$ & $\begin{array}{l}\text { Per } \\
\text { g. } \\
06\end{array}$ & $\begin{array}{l}\text { Per } \\
\text { g. } \\
07\end{array}$ & $\begin{array}{l}\text { Per } \\
\text { g. } \\
08\end{array}$ & $\begin{array}{l}\text { Per } \\
\text { g. } \\
09\end{array}$ & $\begin{array}{c}\text { conformidade } \\
\text { com as leis de } \\
\text { dados }\end{array}$ \\
\hline 1. Delta & & & & & & & & & & \\
\hline 2. Sigma & & & & & & & & & & \\
\hline 3. Omega & & & & & & & & & & \\
\hline
\end{tabular}

As inconformidades foram notadas em quatro das cinco empresas brasileiras avaliadas e estão relacionadas a dois descritores: (1)fornecer informações seguras e claras ao usuário quanto à finalidade do tratamentos de dados; (2) Possuir 
LELIS. Henrique Rodrigues; COELHO, Fernando Da Cruz; LEMOS JUNIOR, Eloy Pereira. O impacto das normas de proteção de dados pessoais nos social customer relationship management. Revista Eletrônica Direito e Política, Programa de PósGraduação Stricto Sensu em Ciência Jurídica da UNIVALI, Itajaí, v.16, n.3, $3^{\circ}$ quadrimestre de 2021. Disponível em: www.univali.br/direitoepolitica - ISSN 1980-7791.

sistemas eficientes de comunicação entre o usuário e o controlador/encarregado de tratamento de dados. Isto significa que as organizações brasileiras precisam aprimorar a transparência e comunicação de suas ações junto ao consumidor e desenvolver protocolos de informação e comunicação com usuários mais eficientes.

Quando analisadas as causas destas falhas, nota-se que estão relacionadas à gestão organizacional e tomada de decisão, pois, não foram percebidos limitações tecnológicas ou problemas técnicos para implementação de medidas corretivas da inconformidade. Trata-se de uma não visualização da gestão empresarial da inconformidade com a LGPD. Ou seja, os problemas estão relacionados à postura da gestão empresarial com o cliente virtual, que desconhecem os riscos que a organização está correndo.

Isto demonstra que, sistemas de Social-CRM e compliance digital devem ser baseados na gestão do conhecimento, com forte posicionamento estratégico na gestão de pessoas e governança corporativa, com uso de ferramentas tecnológicas como suporte operacional, pois, mais importante que ter o acesso a tecnologia, a organização precisa saber o seu propósito, sob o risco não obter resultados, sendo este o ponto frágil notado nesta pesquisa.

A gestão do conhecimento tem se destacado nas organizações como forma de questionar o modelo tradicional vigente, o qual não vem atendendo mais com a mesma eficiência a demanda por mobilidade presente nas organizações e, pela evidência de uma nova forma de diferencial competitivo centrado no ser humano. O conhecimento não é algo novo para as organizações, mas a sua sistematização e utilização como diferencial competitivo é enfatizada pelos modelos de gestão baseados no conhecimento. Em decorrência, várias mudanças são percebidas nas organizações visando à adaptação à nova realidade da sociedade e para compreendê-las é importante entender o que é a gestão do conhecimento. Dazzi; Angelo (2009)

A internacionalização da marca também foi detectada como um influenciador na forma com a qual a organização faz o tratamento de dados pessoais. Empresas que operam em mercados globais, com marcas internacionalmente conhecidas, 
LELIS. Henrique Rodrigues; COELHO, Fernando Da Cruz; LEMOS JUNIOR, Eloy Pereira. O impacto das normas de proteção de dados pessoais nos social customer relationship management. Revista Eletrônica Direito e Política, Programa de PósGraduação Stricto Sensu em Ciência Jurídica da UNIVALI, Itajaí, v.16, n.3, $3^{\circ}$ quadrimestre de 2021. Disponível em: www.univali.br/direitoepolitica - ISSN 1980-7791.

possuem melhores sistemas de conformidade que as empresas atuantes no mercado nacional.

Nota-se que, das 06 empresas que operam com exportação (três brasileiras e três europeias), apenas duas brasileiras apresentaram inconformidades com a legislação de dados, mesmo assim, em apenas duas perguntas. Do outro lado, todas as empresas que operam apenas no mercado nacional, apresentaram inconformidades em 04 ou 05 perguntas, ou seja, em quantidades superiores ao dobro das detectadas nas empresas exportadoras.

Portanto, existe um dado indicativo de uma relação entre a proteção de dados pessoais e internacionalização da economia, pois, o cuidado com a proteção de dados pessoais pode estar mais conectado a preocupação da gestão em acessar mercados consumidores internacionais, com descritores relacionados a cadeias globais de valor, imagem institucional e valorização da marca, do que a eficácia da fiscalização estatal brasileira ou medo da gestão empresarial quanto a possíveis penalizações imposta pelo sistema judiciário brasileiro.

\section{CONSEQUÊNCIAS DA INCONFORMIDADE}

Os efeitos da conformidade legal das empresas brasileiras podem ser divididos em três: legal, comercial e de imagem.

Os sistemas de gestão de dados que não estiverem de acordo com o previsto em lei estarão sujeitos a multas e penalizações impostas pelo Estado, isto significa dispêndios financeiros com defesas jurídicas, perícias, pagamento de multas e indenizações diversas. Certamente, investimentos em prevenção e correção das inconformidades terão um custo inferior às consequências legais.

Há clara limitação ao mercado internacional, pois, empresas estrangeiras farão ressalvas a possíveis parcerias com empresas brasileiras para introdução de seus produtos, pelo risco de contaminação de seus sistemas de compliance digital, com as inconformidades detectadas nos sistemas brasileiros. 
LELIS. Henrique Rodrigues; COELHO, Fernando Da Cruz; LEMOS JUNIOR, Eloy Pereira. O impacto das normas de proteção de dados pessoais nos social customer relationship management. Revista Eletrônica Direito e Política, Programa de PósGraduação Stricto Sensu em Ciência Jurídica da UNIVALI, Itajaí, v.16, n.3, $3^{0}$ quadrimestre de 2021. Disponível em: www.univali.br/direitoepolitica - ISSN 1980-7791.

Por fim, a imagem da empresa junto ao mercado certamente corre o risco de desgaste, pois o próprio usuário tende a ampliar sua fonte de conhecimento e preocupação com seus dados pessoais, provocando a perda de credibilidade e confiança com a marca, face a inconformidade detectada. Portanto, sistemas de Social-CRM precisam ser construídos e devem operar em alinhamento com sistemas de compliance digital.

\section{CONSIDERAÇÕES FINAIS}

Esta pesquisa teve como objetivo estudar os possíveis efeitos que a vigência das leis de proteção de dados pessoais irá trazer para os sistemas de Social- CRM empresariais. Foi desenvolvido um estudo bibliográfico para definição de conceitos básicos e a relação entre os temas, permitindo a correta extração de dados e realização do estudo de caso.

A partir do estudo de caso de 08 empresas atuantes no ramo de alimentos, foi constatado um posicionamento estratégico de participação ativa de todas as empresas nas mídias sociais, incluindo sistemas de gestão e gerenciamento de fluxo de dados digitais com vistas a obter engajamento e manter relacionamento com público-alvo por meio de plataformas digitais, podendo ser afirmado que as mídias sociais digitais são parte estratégicas para as organizações.

A questão relacionada às novas leis de proteção de dados pessoais impactam diretamente estes sistemas de gestão empresarial baseados em mídias sociais, na medida que, a violação dos preceitos legais na condução de operações de SocialCRM levam a penalizações legais e principalmente, perda de confiança do usuário, fluxo de dados negativos a marca com respectiva perda de valor.

Foi constatado que parte significativa das empresas brasileiras não estão adequadas ao previsto em lei, possuindo inconformidades na proteção de dados pessoais, especialmente no que concerne a transparência e acesso à informação ao usuário quanto à finalidade e modo de tratamento de dados digitais. Também 
LELIS. Henrique Rodrigues; COELHO, Fernando Da Cruz; LEMOS JUNIOR, Eloy Pereira. O impacto das normas de proteção de dados pessoais nos social customer relationship management. Revista Eletrônica Direito e Política, Programa de PósGraduação Stricto Sensu em Ciência Jurídica da UNIVALI, Itajaí, v.16, n.3, $3^{\circ}$ quadrimestre de 2021. Disponível em: www.univali.br/direitoepolitica - ISSN 1980-7791.

foi detectado que marcas globalizadas possuem sistemas de proteção de dados mais rígidos e eficazes que marcas operantes em mercados locais. Isto pode ser explicado como sendo o resultado de uma maior preocupação da gestão organizacional em manter a valorização da marca junto ao mercado do que efetivamente, consequências legais de possíveis inconformidades.

Por sua vez, estas falhas estão relacionadas a como os sistemas tecnológicos estão sendo empregados. Ou seja, trata-se de problemas ligados à gestão de pessoas, governança corporativa e tomada de decisão, não sendo detectado falhas tecnológicas ou ausência de ferramentas de suporte operacional. Percebe-se que modelos de compliance digital e Social-CRM são sistemas que operam de forma interconectados, com suas raízes na gestão de conhecimento. Suas estruturas devem ser pensadas a partir do investimento em pessoas e processos gerenciais e devem operar em conjunto de forma a produzir sinergia para atingir um propósito. Desta forma, esta pesquisa contribui para o desenvolvimento do debate acadêmico sobre o tema, destacando-se a valorização do pensamento dialógico e transdisciplinar entre direito, administração empresarial e gestão do conhecimento.

\section{REFERÊNCIAS DAS FONTES CITADAS}

AZURMENDI, A. Derechos Digitales De Los Menores Y Datos Masivos. Reglamento Europeo De Protección De Datos De 2016 Y La Coppa De Estados Unidos. El Profesional de la Información, [s. I.], v. 27, n. 1, p. 27-35, 2018. DOI 10.3145/epi.2018.ene.03. Disponível em: http://search.ebscohost. com/login.aspx ?direct $=$ true $\& d b=a p h \& A N=128404499 \&$ l ang=pt-br\&site=ehost-live. Acesso em: 17 abr. 2020.

BAARS, Hans et al. Foundations of information security based on ISO27001 and ISO27002. Van Haren, 2015.

BARBOSA, Ricardo Rodrigues. Gestão da informação e do conhecimento: origens, polêmicas e perspectivas. Informação \& Informação, v. 13, n. 1esp, p. $1-25,2008$.

Boyd, D. M., \& Ellison, N. B. (2007). Social network sites: Definition, history, and scholarship. Journal of computer-mediated Communication, 13(1), 210-230. 
LELIS. Henrique Rodrigues; COELHO, Fernando Da Cruz; LEMOS JUNIOR, Eloy Pereira. O impacto das normas de proteção de dados pessoais nos social customer relationship management. Revista Eletrônica Direito e Política, Programa de PósGraduação Stricto Sensu em Ciência Jurídica da UNIVALI, Itajaí, v.16, n.3, $3^{\circ}$ quadrimestre de 2021. Disponível em: www.univali.br/direitoepolitica - ISSN 1980-7791.

CARDOSO, Leonor; GOMES, A, Duarte; REBELO, Teresa. Gestão do conhecimento: Dos dados à informação ao conhecimento. Comportamento organizacional e gestão, 2003, vol. 9, N.o 1, 55-84.

CARLOS, JOSÉ; FILHO, ALMEIDA. Direito Eletrônico ou Direito da Informática? Informática Pública vol. 7 (2): 11-18, 2005.

DA CUNHA GUIMARÃES, Antônio Márcio; GUIMARÃES, Gabriel Stagni. DIREITO DIGITAL. DIREITO INTERNACIONAL E GLOBALIZAÇÃO ECONÔMICA, v. 2, n. 02, p. 70-81, 2017.

DA SILVA, Cleber Demetrio Oliveira. Fundamentos jurídicos e tecnológicos do comércio eletrônico no Brasil. Jus Navigandi, 2006.

DAVENPORT, T. H., PRUSAK, L. Conhecimento empresarial: como as empresas gerenciam seu capital intelectual; tradução Lenke Peres. Rio de Janeiro: Campus, 1998.

DAZZI, Márcia Cristina Schivi; ANGELONI, Maria Terezinha. Compreendendo o significado de gestão do conhecimento e a importância da comunicação em seu compartilhamento - um estudo de caso. RAUnP-Ano I, n. 1, v. 1-Out. 2008/abr. 2009, p. 18, 2008.

DE OLIVEIRA, Maxwell Ferreira. Metodologia científica: um manual para a realização de pesquisas em Administração. Universidade Federal de Goiás. Catalão-GO, 2011.

DE PAIVA, Mário Antônio Lobato. Primeiras linhas em direito eletrônico. Boletín jurídico de la Universidad Europea de Madrid, n. 6, p. 11, 2003.

DE SOUZA PIMENTEL, Jose Eduardo. Introdução ao Direito Digital. Revista Jurídica da Escola Superior do Ministério Público de São Paulo, v. 13, n. 1, p. 16-39, 2018.

DOVE, E. S. The EU General Data Protection Regulation: Implications for International Scientific Research in the Digital Era. Journal of Law, Medicine \& Ethics, [s. I.], v. 46, n. 4, p. 1013-1030, 2018. DOI $10.1177 / 1073110518822003$.

Disponível em:

http://search.ebscohost.com/login. aspx?direct=true\&db=aph\&AN=134282677\&l ang=pt-br\&site=ehost-live. Acesso em: 17 abr. 2020.

EVANGELISTA, Marcos. Infodireito em 16 aulas. Manaus: Ebook, 2013.

FERREIRA, Aurélio Buarque de Holanda. Novo dicionário Aurélio da língua portuguesa. In: Novo dicionário Aurélio da língua portuguesa. 2004. p. 20122012. 
LELIS. Henrique Rodrigues; COELHO, Fernando Da Cruz; LEMOS JUNIOR, Eloy Pereira. O impacto das normas de proteção de dados pessoais nos social customer relationship management. Revista Eletrônica Direito e Política, Programa de PósGraduação Stricto Sensu em Ciência Jurídica da UNIVALI, Itajaí, v.16, n.3, $3^{\circ}$ quadrimestre de 2021. Disponível em: www.univali.br/direitoepolitica - ISSN 1980-7791.

FOLEY, Éric; GUILLEMETTE, Manon G. What is business intelligence?. International Journal of Business Intelligence Research (IJBIR), v. 1, n. 4, p. 1-28, 2010.

FULD, Leonard $M$. What competitive intelligence is and is not. Fuentes de información en economía y empresa, 1999.

GREENBERG, Paul. Social CRM comes of age. Sponsored by Oracle, 2009.

KOTADIA, Harish. Definition: What is Social CRM. Social CRM and Business, 2009.

LEONARDI, Marcel. Fundamentos de Direito Digital. Revista dos Tribunais. $1^{\text {a }}$ edição. 2019

Lodder, Arno R., Internet Law: A Brief Introduction (June 6, 2018). SAGE Encyclopedia of the Internet edited by Barney Warf (2018). Available at SSRN: https://ssrn.com/abstract $=3191751$

LOPES, ALAN MOREIRA. Direito Eletrônico aplicado às redes sociais. Clube de Autores, 2013.

MACIEL, Rafael Fernandes. Manual Prático sobre a Lei Geral de Proteção de Dados Pessoais. Digital Education. 2019.

Malhotra, N. K. (2018). Marketing Research: Current State and Next Steps. Brazilian Journal of Marketing-BJMkt Revista Brasileira de Marketing-ReMark Special Issue, 17, 18-41.

MARQUES, Lidiany Kelly da Silva; VIDIGAL, Frederico. Prosumers e redes sociais como fontes de informação mercadológica: uma análise sob a perspectiva da inteligência competitiva em empresas brasileiras. Transinformação, Campinas, v. 30, n. 1, p. 1-14, Apr. 2018. Available from $<$ http://www.scielo.br/scielo.php?script=sci_arttext\&pid=S0103-

$37862018000100001 \&$ lng $=$ en\&nrm $=$ iso $>$. access on $25 / 03 / 2020$.

MARQUES, Margarida Almeida; COSTA, Carlos J. Social CRM analytics. In: 2018 13th Iberian Conference on Information Systems and Technologies (CISTI). IEEE, 2018. p. 1-6.

MONTEIRO, Nabor Alves; FALSARELLA, Orandi Mina. Um modelo de gestão da informação para aprendizagem organizacional em projetos empresariais. Perspectivas em ciência da informação, v. 12, n. 2, p. 81-97, 2007.

MOSADEGH, Mohammad Javad; BEHBOUDI, Mehdi. Using social network paradigm for developing a conceptual framework in CRM. Australian Journal of Business and Management Research, v. 1, n. 4, p. 63, 2011.

PINHEIRO, Patricia Peck. Direito digital. Saraiva, 2009. 
LELIS. Henrique Rodrigues; COELHO, Fernando Da Cruz; LEMOS JUNIOR, Eloy Pereira. O impacto das normas de proteção de dados pessoais nos social customer relationship management. Revista Eletrônica Direito e Política, Programa de PósGraduação Stricto Sensu em Ciência Jurídica da UNIVALI, Itajaí, v.16, n.3, $3^{\circ}$ quadrimestre de 2021. Disponível em: www.univali.br/direitoepolitica - ISSN 1980-7791.

PINHeIRo, Patricia Peck. Proteção de Dados Pessoais: Comentários à Lei n. 13.709/2018 -LGPD. Saraivajur. 2020.

PIPER, A. GDPR' s Global Reach. Internal Auditor,[s. I.], v. 76, n. 2, p. 24-29, 2019. Disponível em: http://search.ebscohost.com/login. aspx?direct $=$ true $\& d b=b s h \& A N=135785018 \&$ l ang=pt-br\&site=ehost-live. Acesso em: 17 abr. 2020.

PIRTTIMAKI, V. H. Conceptual analysis of business intelligence. South African journal of information management, v. 9, n. 2, p. 1-1, 2007.

RANJAN, Jayanthi. Business intelligence: Concepts, components, techniques and benefits. Journal of Theoretical and Applied Information Technology, v. 9, n. 1 , p. 60-70, 2009.

Recuero, Raquel Diga-me com quem falas e dir-te-ei quem és: a conversação mediada pelo computador e as redes sociais na internet. Revista FAMECOS: mídia, cultura e tecnologia [en linea]. 2009, (38), 118128[fecha de Consulta 28 de Diciembre de 2019]. ISSN: 1415-0549. Disponible en: https://www.redalyc.org/articulo.oa?id=495550194016

REINHOLD, Olaf; ALT, Rainer. The Role of Social CRM in Social Information Systems: Findings from Four Case Studies. In: Proceedings of the 52nd Hawaii International Conference on System Sciences. 2019.

RÉVILLION, Anya Sartori Piatnicki. A utilização de pesquisas exploratórias na área de marketing. Revista Interdisciplinar de Marketing, v. 2, n. 2, p. 21-37, 2003.

SILVA, Valdenis Souza et al. Convergência da inteligência competitiva com construção de visão de futuro: proposta metodológica de sistema de informação estratégica (SIE). 2001.

Siriwardana, A., \& Dissanayake, D. M. R. (2018). Social Customer Relationship Management (SCRM) in Contemporary Business Era. International Journal Business and Management Invention (IJBMI), 7(9), 59-64.

TUNICK, David C. Computer Law: An Overview. Loy. LAL Rev., v. 13, p. 315, 1979.

TURATO, Egberto Ribeiro. Métodos qualitativos e quantitativos na área da saúde: definições, diferenças e seus objetos de pesquisa. Rev. Saúde Pública, São Paulo, v. 39, n. 3, p. 507-514, June 2005 . Available from $<$ http://www.scielo.br/scielo.php?script=sci_arttext\&pid=S0034-

$89102005000300025 \&$ Ing $=$ en\&nrm=iso $>$. access on $17 \mathrm{Apr} .2020$.

VALENTIM, Marta Lígia Pomim et al. Inteligência competitiva em organizações: dado, informação e conhecimento. DataGramaZero, Rio de Janeiro, v. 3, n. 4, p. 1-13, 2002. 
LELIS. Henrique Rodrigues; COELHO, Fernando Da Cruz; LEMOS JUNIOR, Eloy Pereira. O impacto das normas de proteção de dados pessoais nos social customer relationship management. Revista Eletrônica Direito e Política, Programa de PósGraduação Stricto Sensu em Ciência Jurídica da UNIVALI, Itajaí, v.16, n.3, $3^{\circ}$ quadrimestre de 2021. Disponível em: www.univali.br/direitoepolitica - ISSN 1980-7791.

VERITAS TECHNOLOGIES. Veritas Prepara a las Organizaciones para el Nuevo y Complejo Reglamento General Europeo sobre la Protección de los Datos (General Data Protection Regulation, GDPR). Business Wire (Español),[s. I.], 2016 dez. 5DC. Disponível em: http://search.ebscohost.com/login.aspx?direct=true\&db=bwh\&AN=bizwire.c6854 2670\&lang=pt-br\&site=ehost-live. Acesso em: 17 abr. 2020.

YAWISED, Kritcha; ELLIS, Leonie; WONG, Ming Chao. A framework for the adoption of social customer relationship management (scrm) by private sector. Asian Journal of Science and Technology, v. 9, n. 4, p. 7844-7851, 2018.

ZANATTA, Rafael AF. Proteção de dados pessoais como regulação de risco: uma nova moldura teórica?. ANAIS Rede 2017, p. 175, 2017. 